\title{
Modeling of Ethno Pedagogical Technologies
}

\author{
Ethno pedagogical theory in education environment
}

\author{
Shavadi Arsaliev \\ Institute of Chechen and General Linguistics \\ Chechen State University, Chechen State Pedagogical University \\ Grozny, Chechen Republic, Russia \\ shavadiarsaliev@gmail.com
}

\begin{abstract}
Ethno pedagogical technologies are considered to be a new kind of technologies connected to national education. Ethno pedagogics represent a new field of education science and study the national experience and traditions of education. It is connected to ethnography, history, psychology, geography and other social and educational sciences permitting to find out and to study national features of different regions. The national education experience can be very useful for the personality development and the cultural competences formation. Multicultural educational environment is considered to be very effective for education process. However, the use of potential of national education is not effective because of the absence of methodology and theoretical base of ethno pedagogics as a science. In this paper, the basic concepts of ethno pedagogics are introduced first. Then the ethno pedagogical technologies are proposed as a special set of educational operations and techniques.
\end{abstract}

Keywords-ethno competence; ethno pedagogics; ethno pedagogical technologies; multicultural education; national education; methodology; pedagogical conditions; educational environment.

\section{INTRODUCTION}

The relevance of the research problem is determined by the complexity of the current stage of development of society, defined as informational. New conditions of formation and development of an individual determine the need to review all installations and principles for determining the success of this process. Ethno pedagogical theory, successfully developing as one of the promising areas of psycho-pedagogical sciences, has a great potential in this context [1]

The impact of modern information field of the personality, its influence and interaction with the personal meanings should contribute to the development of the personal sphere and its improvement. Ethno media, ecological theory, implemented by ethno pedagogical technologies, provide a new level of development of personal sphere, which is characterized by understanding the personality as an active converter of reality and, simultaneously, as a representative of the interests, traditions and practices of a particular ethnic community. In this case, in the personal sphere, necessary balance between the personal and the public, ethnic and national etc. is updated by consideration of the components of ethno pedagogical theory, concepts included in it, taking into account the features of modern informational space. This space is formed, developed, performed and it has a potential in improving personality [2].
The formation and development of ethno cultural identity constitutes one of the strategic goals of the education system. Multicultural world influences a personality. The ability of a member of the society to communicate is connected with the possession of linguistic means, i.e. with the linguistic component in the structure of ethnic and cultural identity. Ethno-cultural identity is formed as a result of ethno-cultural education $[1,2]$. The linguistic component can be represented in the structure of personality in the various options. The role of the linguistic component in the training under the ethnocultural identity is evident. Current situation complication of international relations, evident social stratification of society, increasing tendencies of individualization of the living space of each individual, actualizes the problem of using the potential of ethnic language in the formation, development and improving of the improvement of the identity of the carrier of the ethnic culture $[1,2]$. The solution of this problem will contribute to the development and improvement of ethno-cultural education. Ethno-cultural education is a holistic educational process the development of the content of ethnic culture in the activity experience, the awareness of continuity in the development of ethnic culture (in the broad sense and super ethnos), understanding ethnic and cultural diversity, interaction between cultures, and similarities in them [3]. The specificity of ethnocultural education is in the dominant focus on the study of traditional culture, especially the culture of the native ethnos and super-ethnos (Russian in our country), as well as ethnic cultures of other peoples [4].

Study and exploratory analysis of scientific, philosophical, pedagogical, ethnographic, and ethno pedagogical sources dealing with various aspects of the studied problem, showed its complexity and ambiguity. In this direction, there are three key concepts to be analyzed: information field, an identity and ethno pedagogical theory.

Ethno pedagogics represent a new branch of pedagogical science. Ethno pedagogics is considered as a young and actively developing direction in pedagogics. It represents a scientific knowledge containing the information on practical education and formation of ethnic groups' experience, about moral, ethical and aesthetic views on value of a family, a tribe, a national character, a nation [1]. They can result in factors and principals of education; have a methodological and theoretical base. The object of studies of this science is a national experience and traditions of education. It means that it can be considered as a separate branch of science having its own structure, methods, systems, and applications. 
It was recognized that ethno pedagogics represent a separate option of modern pedagogics studying national educational experience in theoretical and practical application. The development of this science becomes more and more important because of the specificity of Russian education space which is considered to be multinational and multicultural.

Each nation has its own education system based on history, family traditions, national ideas and ideals. This system is connected to ethnic properties and differences of each nation, its geographical position, and ethnographic moments. It reflects national ideas about education. The research approaches and the methods applied in ethno pedagogics are numerous and various. The theoretical conclusions explaining historical and modern functioning of ethnos pedagogical traditions are made on their basis [2].

In this paper, we will first introduce related works on ethno pedagogics. Then we propose the methodological base of ethno pedagogics, the models of ethno pedagogical system, the characteristics of its components, the pedagogical conditions of realization in high school education space, and the model of ethno pedagogical technology.

\section{Ethno Pedagogics in Modern Science}

\section{A. A Short Review on Ethno pedagogics Development}

Initial elements of ethno pedagogical knowledge have arisen in tribe formation as an initial ethnic generality. On an extent of history of a human society development the ethno pedagogical knowledge constantly developed, replenishing with new elements. Generalization of ethno pedagogical knowledge at this stage occurred in products of oral national creativity: fairy tales, legends, proverbs, sayings, and in traditions, customs, ceremonies etc.

Great scientists of the past have studied educational traditions of the ancestors with a big respect and attention. Studying culture of the people including pedagogical elements, they selected all the best in it and included in their scientific papers and students education.

Outstanding Chinese philosopher Confucius (551-479 BC) was one of the first scientists who were engaged in studying and generalization of national pedagogical culture. He has introduced many ethical positions that have become classical in ethno pedagogical theory and practice. For example, a strict norm of behavior and filial respect and sanctity of any young person to the previous generations representatives. In education of children and youth it is necessary to follow cultural traditions; a basis of principles of construction of a perfect social system is humanity, observance of rituals and ceremonies and a practical embodiment of ethical standards in life; studying of traditions and wisdom of ancestors, and also studying of classical works should make a formation basis.

The theoretical bases of the ethno pedagogics which have been put by such greatest teachers as J.A. Komensky, A.S. Makarenko, V.A. Suhomlinsky, K.D. Ushinsky and others, proved continuity in questions of education, necessity of use of a creative heritage of last generations and ethnic educational experience, promoted ethno pedagogics formation as a branch of modern scientific knowledge. The great scientists mentioned above have paid attention to the fact that national educational ideas can be structured and represented as systems. Transformation of ethno pedagogics into independent branch of a science is considered to be a merit of the greatest ethnoteacher of the present, academician G.N. Volkov [3]. Methodological, practical and applied problems of ethnic pedagogics have also been discussed and developed in works by V.G. Afanasjev, Sh.M-Kh. Arsaliev, M.B. Gurtueva, T.N. Petrova, I.A. Shorov and many others. Ethno pedagogics development was promoted also by researches of feature of culture and a life of representatives of a separate ethnos, in particular, the people of the North Caucasus, analyzed by Sh.M-Kh. Arsaliev, M.Kh. Bagaeva, A.I. Karaeva, I.M. Shamanov; the ethic norms of ethnos presented in works by A.I. Musukaev, A.I. Pershits, K.A-K. Salpagarova; the religious aspects of education are studied by A.I. Ibragim, G.M. Shajdaeva, etc.

Being considered to be a modern science ethno pedagogics is influenced by technological approach which is discussed very much in education science.

Overcoming of the modern education system crisis caused by discrepancy of rates of global, technological, ethnic, cultural and educational processes development in transition to an information society is connected with the solution of the formation problem and development of a new type of the person. Deep changes at the present stage of development of a society make new demands to formation of the person in educational space. The person of new type should be ready to ability to live in poly ethnic space, to intercultural dialogue, to creativity in practical and intellectual activity [4].

Revealing of ways and means of decrease in spontaneity elements in ethno pedagogical process, an establishment of the most effective forms and methods of the coordination of objective and subjective factors of national education allow improving the last in modern conditions. One of such ways is the use of the synergetic approach in the ethno pedagogical phenomena studying. Its appearance is connected with changes in a general scientific picture of the world.

\section{B. Synergetic Approach in Modern Ethno Pedagogics}

Post-non-classical strategy of knowledge is only being formed. Thus scientists mark as one of its important lines a special urgency of this strategy not only in modern natural sciences, but also in relation to research problems of social and humanitarian knowledge, in particular to training and education problems.

Post-non-classical strategy of knowledge is directly connected with a so-called evolutionary paradigm, or, other names applied to this paradigm, - a paradigm of Darwin, a paradigm of evolution and synergetics [5]. At the basis of the new approach to the description of various evolutionary processes the modern understanding of evolution as selforganization displays lays. Now a wide spectrum of processes of self-organization both in live, and in the lifeless nature is already studied. 
Synergetics as the new scientific direction investigating processes of self-organization of structures of the various nature, searches for universal laws of occurrence of an order from chaos, makes attempt to create the description of the reasons and mechanisms of steady existence of arising structures and their disintegration [8].

Synergetics is considered as the self-organization theory in the complex, open, non-equilibrium and nonlinear systems of any nature. This is a new scientific direction engaged in studying of occurrence, maintenance, stability and disintegration of self-organizing structures, co-operative effects in them [6].

Synergetics represents a scientific direction studying processes of education and mass (collective) interactions of objects, elements and subsystems [7]. These processes are:

1) happening in open systems (physical, biological, social, also formal and computing) in non-equilibrium conditions;

2) accompanied by an intensive exchange of substance, energy, information and other communication attributes with environment, with possibility of energy absorption, receipt of initial substances and removals of products;

3) characterized by spontaneity (absence of rigid determination from the outside, individual independence, spontaneity) behavior of the objects (subsystems), combined with effect of cooperation;

4) streamlining having by result, self-organization, entropy reduction, also evolution of systems (removal both from chaos and from static character).

Scientists consider synergetics as a set of the general ideas about principles of self-organization and the sum of the general mathematical methods for its description. From a synergetics position the problems still recently entirely concerning sphere of humanitarian knowledge are already analyzed in details. Mathematical modeling of historical processes, global demographic forecasts, strategic planning of the future humankind, forecasts of development of an education system etc. [9] can serve as an example.

According to synergetics positions, a self-organization represents the ability of a weakly structured, stable, open system to self-building, to self-development into new, more viable quality. The basic sources of development of the selforganized systems are internal resources. This property is quite applicable to any pedagogical structure in this connection its concepts receive essentially new and more exact treatment in a humanistic context - occurrence of "an order from chaos" in a human being. G. Haken, I. Prigozhin and I. Stengers's ideas have been extrapolated in sciences about the human being that promoted the appearance of psycho-synergetics and pedagogical synergetics.

According to synergetic paradigm, the whole is always more than a simple sum of parts making it. In ethno pedagogical technologies' designing and realization it means, that the ethno cultural educational space containing different education systems parts, represents a phenomenon possessing qualitatively new properties, in comparison with each separately taken system.
Synergetics has a special methodological value for ethno pedagogics. Formation of a person in ethno cultural space is carried out also in the course of passage of bifurcation points of destruction of old structures and occurrence of new possibilities for system transition in a new quality. This process possesses the property of nonlinearity, i.e. multi-variant approach and unpredictability of transition of system from one condition in another. Ethno pedagogical system is unstable, strong, unbalanced, and fluctual. It is opened for development etc. Attractors are represented by the ethno cultural phenomena. The process of sense creation should be organized so that in this semantic self-organization, formation of a semantic basis of a trainee takes place according to synergetic laws. Self-organization is carried out if a system is unbalanced. Energy or information "are pumped over" a system and it results in system changes. In ethno cultural educational space it is the ethno cultural information. Synergetics speak about attraction zones made by this or that attractor. An attractor represents an area resulting in a trajectory of development [10]. As a result, unstable balance is an indicator of system development. Development proceeds under condition of occurrence of a new non-equilibrium condition of system. With the fact of an attraction in the conditions of the non-equilibrium systems, proved in synergetics, connect the fact of "a semantic attraction" in the conditions of semantic uncertainty of the person, semantic "struggle" in which more important senses [11] become a part of a personality. In our case, these are ethno cultural senses.

For synergetic paradigms of ability to live of society are characteristic such features, as qualitatively new logic of formation of outlook on a basis of synergetic ideas; subjectivization of social interactions; tolerance in social relations; self-organization in ability to live.

Qualitatively new logic of formation of outlook on a basis of synergetic ideas means, first, innovative filling of social and cultural, in our case - ethno cultural space which is realized by an education system, in particular, formed system of the person ethno formation.

Subjectivization of social interactions promotes the decision of a problem of democratization of a social life of a society. Formation of a subject position represents one of innovative problems that are necessary for solving to an education system. Subjectivization in ethno pedagogical processes means actualization of the ethno pedagogical phenomena with a view of formation of the ethno cultural person.

The tolerance problem in social relations is demanded as the factor regulating social and natural in the subject of ability to live through comprehension of their equal importance, through the new logic of thinking, through the synergetic principle of complementarity in social interactions. Tolerance has special value for ethno pedagogics and ethno pedagogical technologies. Tolerance education in interethnic relations promotes mutual understanding, interaction of various cultures and, the main thing, to respect for separate ethno culture as to a part world civilization and cultural process.

Self-organization in ability to live represents a category demanding the analysis and structuration. Self-organization 
happens without any influence from the outside. One condition of system loses stability, and instead of it, a new steady condition appears. According to features of ability to live we suggest to structure self-organization as psychological, activity, educational and in its system the ethno cultural.

Psychological self-organization in own consciousness of members of society assumes aspiration to harmony and is carried out by resolution of problems, elimination of contradictions, overcoming of discrepancies between own requirements, internal norms and the reached level of development of abilities.

Activity self-organization of society and social systems members is also based on problem comprehension as real obstacle that is necessary for overcoming.

Educational self-organization is realized in change of the person's own consciousness and activity based on social and cultural development. There is a purpose defining sense of actions. Internal norms are modified in search of a new information in external (the reproductive maintenance) and internal (the productive maintenance).

One of kinds of educational self-organization is ethno cultural self-organization that consists in transformation of consciousness and activity of the person on the basis of ethno cultural development.

Generalizing aforesaid, we propose the following synergetic principles of the ethno pedagogics which operating concerns the ethno cultural phenomena and has appeared in connection with transformation of a general scientific picture of the world:

- a principle of a subject; a trainee and a teacher are active subjects of ethno pedagogical process;

- the principle of complementarity, consists that contrasts as a development basis are eliminated not by means of removal, and at the expense of mutual addition, the compromise, former contrasts combining line; in practice it means, that the ethnic cultural monologue gives way to semantic interethnic intercultural dialogue, interaction, partnership, orientations to real freedom of the developing ethno cultural person, national tolerance and a recognition of self-value of each culture;

- a principle of an openness of the ethno cultural information; the role of the teacher consists in placing ethno cultural knowledge offered the trainee in an opening context, to stimulate knowledge process, instead of to give knowledge in a ready kind; the openness of the ethno cultural information means also general availability;

- a principle of nonlinearity of the person ethno cultural development; this principle means that formation of the ethno cultural person happens to the account of variants and development scenarios plurality; nonlinearity is connected with a choice of a way of development which is realized by the person according to own personal senses; in ethno pedagogics personal senses are connected with national consciousness;
- a principle "whole is more than the simple sum of parts»; it means consideration of each separate ethno culture as parts of world cultural process, as integral component of a world civilization;

- a principle of a recognition of each person self-value; from positions of synergetics the person is open possibility; the recognition of self-value of the person means a recognition of its individuality, feature and, at the same time, a recognition of the importance of development of each person for all society;

- a principle of fluctuation (deviation); any functioning system is not stable, in it deviations which conduct to chaos inevitably collect and can even cause its disintegration; process of comprehension itself in ethno cultural space leads «to an order through fluctuation»; it means, that development of the person in ethno cultural space leads to accumulation of the certain ethno cultural information which enters the person into the instability condition which result is occurrence of new personal senses, ideals, installations;

- a principle of discrepancy of development; selforganization is possible at heterogeneity of system, in the presence of no equilibrium structures; development in synergetics is understood as self-actualization of available potential possibilities of system, instead of as putting in order from the outside; development is possible only in case of need overcomings of contradictions;

- a principle of the common rate of development; training and trained in development in ethno cultural space; in the course of evolution open no equilibrium systems are integrated into the complex complete structures developing in different rate.

These synergetic principles of ethno pedagogics operating in ethno cultural space, allow understanding mechanisms of development of the ethno cultural person in which basis lay general scientific synergetic ideas developed in modern science. They allow confirming once again universality of mechanisms of development of the nature and a society, unity of bases of existence.

Being independent branch of a pedagogical science, ethno pedagogics is considered as the powerful tool of maintenance of reproduction of the ethnos, promoting formation of national consciousness of the population, providing transmission of ethnic norms and values from generation to generation. The primary goal of ethno pedagogics is the permission of existing contradictions between necessity of mastering by people this experience and absence at them aprioristic ability to such development, between processes of self-organization of ethnos and the person, growth of ethnic identification and requirement for interethnic integration.

\section{Ethno Pedagogical System and Technology}

The term "technology" is discussed very much in modern pedagogical science. Technology means certain degree of formalization. In ethno pedagogical research technologies only 
start to appear. However, there are no doubts any more that the future pedagogics development is connected to technological approach.

Working out of bases of realization of ethno pedagogical process includes three components as shown in Fig.1.

Working out of the substantial party represents selection, ordering, the analysis, formation of its information component, and consideration of the maintenance of ethno cultural competences. The purpose of ethno pedagogical process is defined as formation of ethno cultural competences. Selection of already existing and creation of new tutorials represents the organization of material base of ethno pedagogical process practical realization. It includes literatures, presentations, equipment etc. Activity working out means working out of the algorithms representing sequence of operations that will be carried out by various participants of ethno pedagogical process.

The ethno pedagogical technology model has been based on universal model of the pedagogical technology $[1,2]$ allowing to track not only sequence of operations in its working out and realization, but also to designate links between its structural components. The model' block diagram is presented on Fig.1.

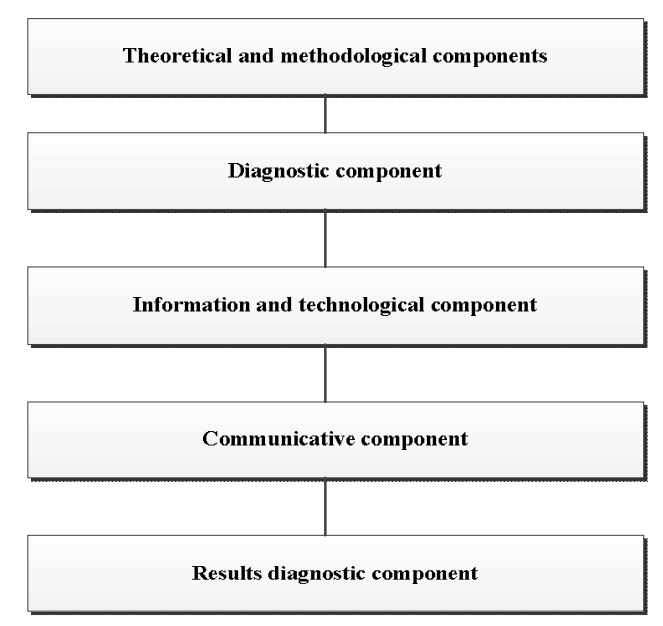

Fig. 1. The block diagram of ethno pedagogical technology model

The theoretical and methodological component of model contains:

- The training and education purpose taking into account the social order of a society in the state educational standard and requirements for formation and development of the trainee personality.

- Hierarchy of methodological approaches to working out of ethno pedagogical technology.

- Ethno pedagogical problems that should be solved during technology realization.

- Pedagogical principles and pedagogical conditions of its realization.

The organization of teaching and educational process is based on some approaches selected by a teacher. The modern scientific analysis proposes a four-level hierarchical system of methodological approaches that we will assume as a basis [1]. All levels of ethno pedagogics methodology form a complex system. The elements of this system and all the links between them are considered and analyzed with use of the following approaches. The highest level is presented by philosophical and axiological forms of humanitarian knowledge of occurrence, formation and development of historical subjects of different scale (persons, nationalities, ethnos, the nations, the people), genetic and evolutionary approaches. The general scientific level is presented by system, integrated, synergetic, sense oriented, and paradigm approaches. The concrete scientific level is presented by personality focused, cultural, anthropological, activity and sense oriented approaches. The methodical level is presented by technological, communicative, and problem oriented approaches.

Let us characterize specificity of some approaches in ethno pedagogics.

Use of the genetic approach in research of the social phenomena and processes means their consideration on the basis of the analysis of their origin and development. Addressing to ethno pedagogical processes, we will notice that the genetic approach in studying of the ethno pedagogical phenomena allows to analyze conditions of an origin and to predict the subsequent development of certain ethnic features of educational systems of the various people, the ethno pedagogical phenomena and processes. It also allows us to reveal the moments of change of ethno cultural competence level and to investigate the mechanism of occurrence of already developed qualities and characteristics of ethno pedagogical process and its subjects.

On the basis of the evolutionary approach [2] ethno pedagogical space is considered as developing social system, its functioning - an integral part of global evolutionary process, and its change occurs according to the general universal algorithms of development.

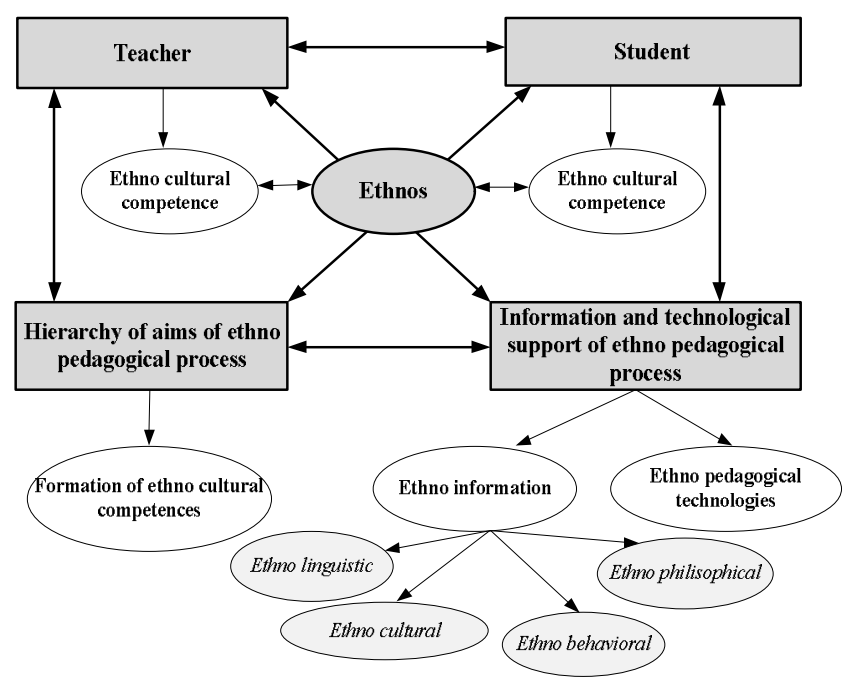

Fig.2. Structure of ethno pedagogical system

Thus, reliance on ethno pedagogical theory in the formation of personality implies the following: 
- Formation of civic identity - the formation of attitudes that allow the individual to relate national and ethnic citizenship, that is, to identify myself as a citizen of a multinational state and, simultaneously, a citizen of a certain region; values, to ensure the balance of national and regional citizenship.

- Formation of ethnic and regional identity - formation of a wide range of knowledge on the history, ethnography, customs and traditions of his native land, region.

- Cultural identity - the formation of knowledge in the field of culture, installations, identifying himself as a representative of the regional (ethnic) culture and national Russian culture, but also as an active participant in the world cultural process.

- Formation of human identity - formation of the installations, allowing to be the bearer of universal values.

The main condition of the successful use of ethno pedagogical theory in the formation and development of personality - complexity, implying the presence of elements of ethnic and cultural knowledge in all educational disciplines, from the study of ethnic language and literature and ending with the formulation of mathematical and physical problems based on ethnic and cultural topics.

It is the solution of tasks of formation of all types of identity-focused development of modern ethno pedagogical theory, which is based on the ethnic pedagogical system, shown in Fig. 1. [Arsaliev, p.]. In our opinion, an essential element of ethno pedagogical system is the ethnic group, as it defines the features of this type of systems. In this case, ethnicity acts as a carrier of ethnic characteristics, ethnic character, ethnic culture, and includes pedagogical elements. Therefore, the ethnic group located in the center of the system, ensuring all communication of other elements of the system. Note that we consider the ethnic group exists in conditions of a multinational state, so there are concepts associated with a specific ethnic group (ethnic features, ethnic culture, ethnic character), and concepts, suggesting that this ethnic group exists in a multi-ethnic state (national culture, national characteristics, national character, etc.). That is, it presupposes the existence of separate ethnic groups within a single nation, for example, ethnicity, Chechens, Kalmyks, Karachais, etc., a nation - the Russians, combining all the existing ethnic groups, including, and Russian.

In the personality of the teacher and pupil, we have also focused on ethno ambitions, which is part of the personality structure and is related to belonging to a particular ethnic group. The difference is that the teacher has the competence to possess, and the pupil we form and develop, that is its presence the pupil is the purpose of ethno pedagogical system.

The hierarchy of objectives of ethno pedagogical process is the system of objectives, the implementation of which will lead to the formation of ethno-cultural identity. We are talking about the hierarchy, because it includes all the goals, ranging from global, in the scale of civilization, society and state, and ending with a specific ethno pedagogical challenges in the educational process.

Information-technological maintenance of ethno pedagogical process has two components: information (content) and process (activity). In the information component we focus on ethno cultural information (in accordance with the structure of the ethnic culture), which interacts with the pupil to the ethno pedagogical process, and differentiate the following components: ethno-linguistic (native language; folklore; ethnic and art (folk art; folk arts and crafts; play; aesthetics of architecture; choreographic aesthetics; the aesthetics of the household; behavioral (attitudes towards women; ethics of family relationships; people's aesthetic ideal; the aesthetics of folk customs and traditions); ideological (the ideological constructs; moral category; the cult; the aesthetics of the natural environment, etc.) [18]. The technological component involves ethno-pedagogical technology of realization of ethno pedagogical process.

The system approach in ethno pedagogics means the consideration of a system of the methodological bases of ethno pedagogical process and its information and technological maintenance. It also means the consideration of ethno cultural competence of the trainee and the teacher as systems, and as element of complete system of personal properties of the person. It is the designing of complete ethno pedagogical process and ethno pedagogical technologies, and their experimental approbation with the subsequent analysis and use of results in practice of educational institutions.

The analysis of background, history, conditions, and prospects of development of ethno pedagogics and the ethno pedagogical phenomena is carried out according to the logic and historical approach. The history of development of ethno pedagogical ideas allows to understand deeply a current state of the theory and to define tendencies of its further development.

According to the integrated approach development of the ethno cultural phenomena represents one of stages of selfimprovement of the person, movement to the person with high level of the ethno cultural competence [12]. Use of the integrated approach in working out of a methodological basis of ethno pedagogics means integration of the above-stated four levels of the analysis. The integrated approach in ethno pedagogics means integration of cultures into poly cultural educational space, consideration and analysis of the ethno cultural phenomena from positions of representatives of various cultures; consideration of any ethnos as world civilization integral part. It assumes comprehension by the person of necessity of possession by high level of ethno culture as success pledge in the further growth and development of the person, consciousness at all stages of realization of ethno pedagogical technologies. In information-technological maintenance of ethno pedagogical process the integrated approach means optimum use of all methods and the forms, all channels of perception of the information, and formed ethno cultural competence is considered as the difficult, multilevel, multidimensional integrated phenomenon entering into system of personal qualities of the person. The integrated approach to the maintenance of ethno pedagogical technologies is shown in 
complex studying of the ethno cultural phenomena as integral part of world cultural process.

Use of the cultural approach in working out and realization of ethno pedagogical technologies means the creation of the poly ethnic educational system for multinational state, the coexistence of multi levels cultures; synthesis of domestic culture with culture of other people; integration into world culture; translation of own national culture coinciding with ethno cultural points of view of trainees and their families.

The concrete definition of methods, approaches and ways of scientific knowledge is carried out at methodical level which is presented technological and communicative approaches.

The technology starts with the formulation of the purpose of realization which, as a rule, is formulated as formation of ethno cultural competence and development of the person of the trainee.

Further the teacher formulates the specific targets conducting to realization of the purposes, analyzes pedagogical conditions of realization of the given technology, pedagogical principles of training and education of the ethno cultural person. All it makes a theoretical basis of the future technology, its methodology allowing the teacher to compare the purpose methods and means.

The structure of a diagnostic component of ethno pedagogical technology includes two kinds of diagnostics: diagnostics of initial level of the ethno cultural competence for the organization of ethno pedagogical process and diagnostics of personal features of trainees for the purpose of optimization of educational and educational process in respect of a choice of means and training methods. In addition, diagnostics of types of the person of trainees, diagnostics of leading modalities of perception, the ethno cultural competence level diagnostics etc. Because of diagnostics, the teacher receives the information on a contingent of trainees that allows it to start further working out and updating ethno pedagogical technologies.

The structure of an information and technological component includes:

- Information component or the ethno cultural maintenance of training representing an information component of ethno pedagogical technologies; the set and the description of ethno cultural competences (formed properties of the person).

- Technological component containing everything that is connected with a remedial part of ethno pedagogical technologies: organization forms; methods of formation of ethno cultural competence; a quality monitoring; algorithms of the ethno pedagogical technologies, reproducing sequence of actions in ethno pedagogical process.

System use of both components in their interrelation and interaction, taking into account technical and human resources allows the teacher to organize active information interaction with trainees for the purpose of the guaranteed achievement of the didactic and educational purposes. We will notice that the training and education maintenance includes not only the educational and educational information, but also its forms, strategy of representation, storage, processing and reproduction.

All information necessary for the teacher and the trainee, both in the course of individual activity, and in the course of their interaction, is given by means of tutorials and education. Integration of these two components of informationtechnological maintenance of educational process consists in it. Forms of teaching and educational process - it is dialogue variants between the teacher and trainees in the educational process, regulating a parity between individual and collective components in training, degree of activity of trainees in education activity.

The system and principles of interaction of subjects of ethno pedagogical process on the basis of equality and cooperation, mutual support and the help are presented in a communication component [16].

The ethno pedagogical technology ends by final results diagnostic component allowing the teacher to define degree of achievement of result of ethno pedagogical technology realization [17]. Ethno cultural competence is formed as the property of the person shown in objective representations, knowledge of ethnic cultures, abilities, skills and the models of behavior promoting effective interethnic mutual understanding and interaction is formed during the polyethnic formation.

The technology of designing of ethno pedagogical process represents the working out of ethno pedagogical technology including designing of the maintenance, choice of means of its representation and working out of algorithm, see Fig.3.

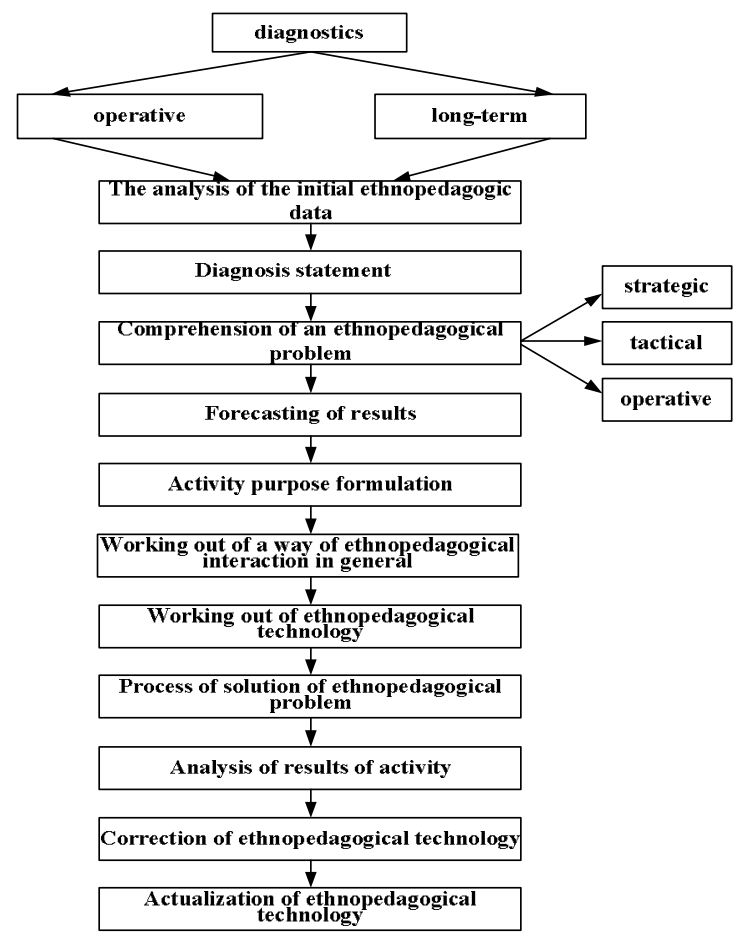

Fig.3. Algorithm of modeling ethno pedagogical technology

Comprehension of an ethno pedagogical problem is an indispensable condition of its productive decision that 
predetermines the analysis of the initial data and diagnosis statement. The analysis of the initial data includes the definition of a place of the developed ethno pedagogical situation. It should be directed on explanation of a condition of its basic components: tutors, pupils and character of the relations that have developed between them; the ethno cultural maintenance; available funds and conditions in which ethno pedagogical process is carried out. Diagnostics can be operative, that is be under construction on the analysis of behavior, activity in concrete situations, the psychological condition, separate acts, or long-term which takes into consideration separate lines of individuality of the pupil, results of numerous supervision etc. Because of the analysis of the initial data the statement of the diagnosis representing an estimation of general is carried out

Diagnosis statement comes to the end with comprehension of an ethno pedagogical problem, and at its three levels strategic, tactical and operative [8]. Comprehension of essence of an ethno pedagogical problem allows the teacher to present result that he would like to reach, solving the given problem that is to predict the future. Purposes development, allowing the teacher to pass to designing of a way of the ethno pedagogical interaction, including also methods, receptions is finished by a prediction phase. It defines end of a stage of designing and transition to a stage of realization of ethno pedagogical technology that is the decision of an ethno pedagogical problem. Results of the decision of an ethno pedagogical problem should be necessarily analyzed that will allow the teacher to introduce further corrective amendments in structure and the maintenance of the developed ethno pedagogical technology.

At a stage of actualization of ethno pedagogical technology it comes to the end but it does not finish. Actualization means further use of ethno pedagogical technology by other teachers, its correction, perfection and modification. Its formalization means the occurrence of possibility of its reproduction not only by the author, but also by other teachers.

\section{CONCLUSION}

Representation of ethno pedagogical technology as sequences of actions will allow each new teacher working with technology to modify it, to introduce his own corrective amendments, to improve and adapt it according to one's own necessity and, hence, to give life to already own variants of ethno pedagogical technologies.

We can see that modeling of ethno pedagogical system and technology gives us the possibility to characterize their main components and elements, to present the sequence of pedagogical operations and activities.

\section{REFERENCES}

[1] Sh. Arsaliev, Ethno pedagogics in a Context of a Modern Scientific Paradigm. Palmarium Academic Publishing. Deutschland. 2013, 285 p. ISBN 978-3-659-98363-4.

[2] Sh. Arsaliev, Methodology of Modern Ethno pedagogics. Moscow: Gelios ARV, 2013, 320 p. ISBN 978-5-85438-224-3.
[3] G. Volkov, Etnopedagogika. Moscow: Publishing centre "Academy", 1999, 168 p. ISBN 5-7695-0413-7.

[4] Sh. Arsaliev, G. Volkov, Ethno pedagogical Values, Tendencies and Prognoses. Izvestya Chechenskogo Gospedinstituta. Grozny. 2009, №2, pp.28-44.

[5] V.N. Lozovsky, S.V. Lozovsky, Concept of Modern Natural Sciences: the manual. 2 edition, corr. - SPb.: Publishing house "LAN". 2006,224 p.

[6] G. Haken, Mysteries of the Nature. Synergetics: The Doctrine about Interaction. Moscow - Izhevsk: Institute of computer researches, 2003, 320 p.

[7] Synergetics. Seminar works. Volume 3. Materials of a round table «Self-organization and synergetics: ideas, approaches and prospects». M: Moscow State University Publishing house. 2000,368 p.

[8] E.N. Knyazeva, Synergetics as a Symptom (the review of the book «The Sinergetics paradigm. Education synergetics. - M: Progresstradition, 2007).

[9] E. Knyazeva, A.Tourobov, Unique Science about the Uniform Nature. The New world. 2000, № 3.

[10] V.G. Budanov, Methodology of Synergetics in Postnonclassical Science and Education. Edition. 3, comp. - M: the Book house «Librocom», 2009, 240 p.

[11] V.V. Suvorov, Synergetic Concept of Self-Organization. In the book. "Synergetics. Seminar works. Volume 3. Materials of a round table" Self-organization and synergetics: ideas, approaches and prospects "M: Moscow State University Publishing house. 2000, pp.325-337.

[12] K. Uilber, Integrated psychology: Consciousness, Spirit, Psychology, Therapy [Text] / K.Uilber; the lane with English; under the editorship of A.Kiseleva. - M: Open Company «nuclear heating plant Publishing house», 2004, 412 p.

[13] V.A. Slastenin, I.F. Isaev, A.I. Mishchenko, E.N. Shijanov, Pedagogics. Moscow, 1998.

[14] K.Silber, The Field Of Educational Technology : A Statement Of Definition. Audiovisual instruction, 1972, № 8. pp. 18-30.

[15] C.Wedemeyer, The future of educational technology in the USA // G. Moir(ed). Teaching and Television, ETV Exp.- Oxford, 1967, pp. 130138.

[16] Z.Werner, Hirsch, Luc E. Weber, Challenges Facing Higher Education at the Millennium. IAU Press. Pergamon. 1999.

[17] P.D. Mitchell, Educational Technology //The Ene. of educational media communications and technology/ Ed. D. Unwin, R. Me. Aleese. - L.,1978, pp.132-185.

[18] Sh. Arsaliev, The Synergetic Approach In Ethno pedagogics. Science, Technology and Higher Education: materials of the V International research and practice conference, Westwood, June 20th, 2014.Publishing office Accent Graphics communications. Westwood. Canada, 2014, 508 p.

[19] [19] Sh. Arsaliev, V. Pisarenko, System Approach as Methodology of Ethno pedagogics. European Social Science Journal. Moscow.2014, №2 (41), vol. 1, pp. 34-42. 